\title{
Effect of child health status on parents' allowing children to participate in pediatric research
}

Jérémy Vanhelst ${ }^{1,2^{*}}$, Ludovic Hardy ${ }^{1}$, Dina Bert ${ }^{1}$, Stéphane Duhem ${ }^{1,3}$, Stéphanie Coopman ${ }^{1}$, Christian Libersa ${ }^{1,4}$, Dominique Deplanque ${ }^{1,4}$, Frédéric Gottrand ${ }^{1,2}$ and Laurent Béghin ${ }^{1,2}$

\begin{abstract}
Background: To identify motivational factors linked to child health status that affected the likelihood of parents' allowing their child to participate in pediatric research.

Methods: Parents were invited to return their completed questionnaires anonymously to assess motivational factors and factors that might improve participation in pediatric research.

Results: Of 573 eligible parents, 261 returned the completed questionnaires. Of these, 126 were parents of healthy children (group 1), whereas 135 were parents of sick children who were divided into two groups according to the severity of their pathology, i.e., 99 ambulatory children (group 2) and 36 nonambulatory children (group 3). The main factor motivating participation in a pediatric clinical research study was "direct benefits for their child" (87.7\%, $100 \%$, and $100 \%$ for groups 1, 2, and 3, respectively). The other factors differed significantly between the three groups, depending on the child's health status (all $p<0.05$ ). Factors that might have a positive impact on parental consent to the participation of their child in a pediatric clinical research study differed significantly $\left(x^{2}\right.$ test, all $p \leq 0.04)$, depending on the child's health status. The main factor was "a better understanding of the study and its regulation" for the healthy children and ambulatory sick children groups (31.2\% and $82.1 \%$, respectively), whereas this was the third factor for the nonambulatory sick children group (50\%).

Conclusions: Innovative strategies should be developed based on a child's health status to improve information provision when seeking a child's participation in pediatric research. Parents would like to spend more time in discussions with investigators.
\end{abstract}

Keywords: Ethics, Pediatric research, Parents' acceptance, Motivation

\section{Background}

There is an increasing need in pediatrics to perform agespecific clinical trials to improve drug safety and to ensure that the best medical treatment is available to children [1]. Therefore, the requirement for high-quality pediatric clinical research studies is growing in industrial and academic organizations [2-6]. In this context, regulatory and ethical considerations have led to the development of specific pediatric regulations and guidelines [7-9].

Recruitment remains one of the main difficulties in clinical research [10,11]. Good Recruitment Practices were published by Bachenheimer and Brescia, but these

\footnotetext{
* Correspondence: jeremy.vanhelst@chru-lille.fr

'Centre d'Investigation Clinique, CIC-PT-9301-Inserm-CH\&U, Lille 59037, France

Unité Inserm U995 \& Université Lille Nord de France, Lille, France Full list of author information is available at the end of the article
}

guidelines fail to consider adequately the responsibilities of parents who care for their children, particularly the following issues [12,13]: $(i)$ the participation of children requires consent from their parents, (ii) children are a vulnerable population, and invasive procedures and pain should be limited as much as possible, (iii) the time constraints of studies may have consequences for the family structure and organization (e.g., jobs, school attendance, and siblings), and (iv) parents have a negative perception of participation in medical research [14-20]. Thus, Lasagna's law (i.e., the "number of patients in the predictive pool always exceed those eligible, which again exceeds those who consent during the recruitment period of the study") may have a greater impact on pediatric studies than on adult clinical studies. The involvement of parents in the health care of their child

\section{Biomed Central}


and the parental perception of pediatric clinical research studies may also affect the study design, particularly with invasive studies [21-23].

Thus, investigators need to present parents and children with a well-balanced view of the risks and benefits of studies and to provide explanations for any procedures involved in pediatric clinical research studies. The majority of research into the participation of children and adolescents in research has focused on the child's understanding of pediatric clinical research studies [24]. Some previous studies have addressed the motivation of parents during the enrolment of their children in pediatric clinical research studies, but there have been no previous investigations of whether the health status of their child might affect parental consent to involvement in pediatric clinical research studies [8,25-28]. We hypothesized that the parents of sick children who had grown up with the rules and regulations of the health care system may have a specific perception of pediatric clinical research studies that could affect their motivation when making a decision about participation in pediatric clinical research studies [16].

The primary aim of this study was to identify motivational factors linked to child health status that affected the likelihood of parents' allowing their child to participate in a pediatric clinical research study. We also aimed to identify key factors that might increase the probability of parents' allowing their child to participate in a pediatric clinical research study.

\section{Methods}

\section{Participants}

Between 2004 and 2007, 22 pediatric clinical research studies were conducted at Lille Clinical Investigation Center (Lille University Hospital; CIC-PT-9301-Inserm$\mathrm{CH} \& \mathrm{U}$, Lille, France), and 18 met the selection criteria. The selection criteria were: $(i)$ pediatric clinical research study conducted between 2004 and 2007, and (ii) child aged between 1 and 18 years. The exclusion criteria were: $(i)$ pediatric clinical research studies involving neonates hospitalized in the intensive care unit, (ii) children enrolled in oncology pediatric clinical research studies, who were considered to be a highly specific group of patients with an immediate, potentially poor outcome, (iii) babies enrolled in industrial milk formula studies, and (iv) other studies involving children aged less than one year. A summary of the recruitment process is shown in Figure 1. The children were divided into three groups according to their disease severity to assess their participation in pediatric research. This

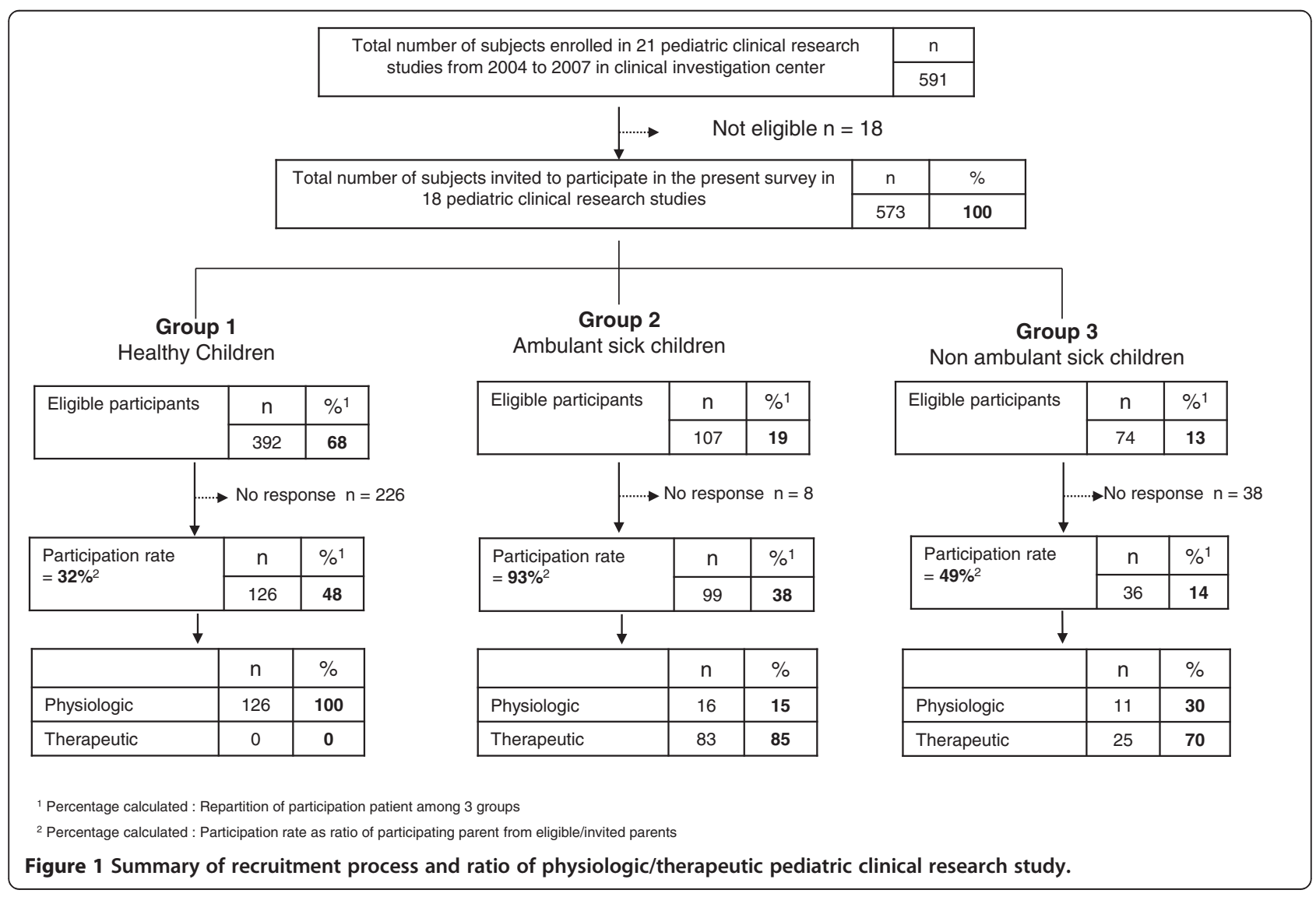


classification was clinically relevant because it can assess the severity of diseases based on their impact on the quality of life, and it can also be used as an indicator of functional ability. Thus, we decided to separate the group of sick children into two subgroups because we hypothesized that the severity of the pathology had different effects on participation in clinical research [29]. Group 1 contained healthy children $(\mathrm{n}=392 ; \mathbf{6 8 \%})$. Group $2(\mathrm{n}=107 ; \mathbf{1 9 \%})$ contained children with diabetes, asthma, cystic fibrosis, phenylketonuria, and gastroesophageal reflux disease. Group $3(n=74 ; 13 \%)$ contained children with severe handicaps such as myopathy and encephalopathy. Physiological pediatric clinical research studies included $100 \%$ healthy children, whereas $85 \%$ and $70 \%$ of the children in the sick groups were included in therapeutic pediatric clinical research studies, i.e., ambulatory and nonambulatory sick children, respectively.

This study was approved by the local research ethics committee (Comité de Protection des Personnes Nord Ouest IV, Lille, France). This study did not involve any interventions and it was retrospective; thus, informed consent was not required according to French human research regulations. The answers provided by parents were anonymous and confidential, and so informatic personal data regulatory authority approval was not necessary to conduct this survey.

\section{Questionnaire}

The questionnaire was written by a focus group of highly skilled professionals (CIC 9301 INSERM-CHU, Lille, France) with experience of pediatric clinical research studies, including a pediatrician, a physician, a member of the local Ethical Review Board, a psychologist, a clinical research assistant/scientist, a study coordinator, and a study nurse. Before data collection, an initial pretest questionnaire was completed by a sample of 10 parents. This pretest was conducted to evaluate the clarity, comprehensiveness, and acceptability of each question, and the questionnaire length. A second pretest (pilot study) was completed by a second sample of 15 parents to assess the quality and response rate for each question. Questions were deleted if they were completed by less than $80 \%$ of subjects. After each step, appropriate changes were made to produce the final questionnaire.

The final questionnaire was divided into three parts: part one: demographic and social information, and the child's medical condition; part two: motivational factors; and part three: factors that could improve pediatric clinical research study participation. The demographic information (part one) comprised the age of the participant, the age of the child, and the parental education level. The parental education level was reported using four categories; i.e., pre-primary school level $($ score $=1)$ to high school (tertiary) level $($ score $=4)$, according to the International Standard Classification of Education structure (www.ins.unesco.org/publications/ISCED97). In the current analysis, the two lower classes were merged into one (i.e., pre-primary education and primary education) to give the following classification: low, medium, and high.

Questions concerning motivational factors (part two) (Additional file 1: Annex 1) were classified into four categories: (i) understanding the study and its regulation, (ii) direct benefits to the parent's own child of participating in the study, (iii) benefits to the general population, and (iv) low risk to the child of participating in the study. The answers to these questions were a simple binary choice; i.e., a "yes" or "no" format.

Questions about factors that might improve parental consent to involvement in pediatric clinical research studies (part three) (Additional file 1: An nex 1) were also divided into four sections: (i) understanding the study and its regulation, (ii) direct benefits to the parent's own child, (iii) low risk to the children, and (iv) the modalities whereby information was communicated about the study. The answers to these questions were a simple binary choice; i.e., a "yes" or "no" format.

A rank order was defined for the two topics and the methodology was as follows. 1. Asking a list of questions in a random order with a "yes/no" reply format. 2. Regrouping the questions depending on the specific items we wanted (four questions for each item) to address. For each parent, we calculated the percentages of "yes" answers and ranked the item as positive if it received $3 / 4$ "yes" replies to these questions (but negative if it received $\leq 2$ ). 3 . We pooled all of the results to determine the global percentage of agreement or disagreement at the group level.

Each questionnaire was introduced by an informative letter, which explained the objectives of the survey, and a guarantee that the data would remain strictly anonymous/confidential.

\section{Survey procedure}

After completing a pediatric clinical research study, the investigator invited parents to answer a set of questions concerning their motivational factors and other factors that might improve pediatric clinical research study participation. The questionnaires were completed after the parents and their children returned to their homes. The parents were invited to return their answers anonymously via the postal system. The replies were anonymous so reminders were not possible. 


\section{Statistics}

\section{Sample size calculation}

The requisite sample size was calculated using data from Van Stuijvenberg et al. [30]. Van Stuijvenberg et al. reported that the major reason (32\%) why parents of sick children agreed that their children could participate in a pediatric clinical research study was a benefit to their own child. No previous data were available to allow a comparison between healthy children and different groups of sick children (ambulatory $v s$ nonambulatory), and so we calculated the sample size using healthy $v s$ a single group of sick children. We assumed that the number of consecutively healthy children recruited would be twice the number of sick children. If we consider a difference of $30 \%$ between groups (62\% for healthy vs $32 \%$ for sick children), with $80 \%$ power and an alpha risk of $5 \%$, the required sample size would be 64 healthy children and 32 sick children. Our objective was to detect the difference between healthy children and each group of sick children (ambulatory and nonambulatory); therefore, the size of each group of sick children was set to $\geq 32$.

\section{Statistical analysis}

The data were analyzed using the Statistical Package for the Social Sciences, version 11.5 for Windows (SPSS Inc., Chicago, IL, USA). Student's $t$-test was used to compare the characteristics of the parents and children. The results of the questionnaires were expressed as the percentages of participating parents who answered "yes" or "no" to each item. The $x^{2}$ test was used to compare differences in the response rates for the healthy and sick groups in terms of the motivational factors and improvement factors. A $p$ value of $<0.05$ was considered significant.

\section{Results}

\section{Participation rate and main characteristics of the} participating parents

Of 573 eligible parents, 261 questionnaires were completed and returned, giving an overall participation rate of $45.5 \%$. Among this population, 126 (48\%) were parents of healthy children (group 1), 99 (38\%) were parents of ambulatory children (group 2), and 36 (14\%) were parents of nonambulatory children (group 3), and these proportions differed from those observed initially in the target population (i.e., 68\%, 19\%, and 13\%, respectively; $X^{2}$ test, $\left.p<0.01\right)$. The participation rate was significantly different between the three groups $\left(\chi^{2}\right.$ test, $p<0.01)$. Parents of ambulatory sick children had the highest participation rate (93\%). The parents who returned the questionnaires answered an average of $98.5 \%$ of the questions.
The age characteristics of the participating parents and children did not differ between the three groups (Table 1). However, the majority of the participating parents were the children's mothers (> 82\%). The parental education level was different between the groups ( $\chi^{2}$ test, $p=0.004$ ). Table 1 also shows that $25 \%$ of ambulatory and $26 \%$ of nonambulatory sick children had participated in a previous pediatric clinical research study whereas only $10 \%$ of healthy children had participated previously $(p=0.83)$. Moreover, $79 \%$ of the parents of ambulatory sick children and $87 \%$ of the parents of nonambulatory sick children had already heard about pediatric clinical research studies compared with $52 \%$ of the parents of healthy children $(p=0.002)$.

\section{Motivational factors}

The main factor motivating participation in a pediatric clinical research study (Table 2) was "Direct benefits for their child" (87.7\%, 100\%, and 100\% for groups 1, 2, and 3 , respectively). The other factors differed significantly between the three groups, depending on the child health status (all $p<0.05$ ).

The main reason for parents' consenting to the involvement of their healthy children was a significantly "low risk" of participating in a pediatric clinical research study (100\%). General benefit to science and health was the second motivational factor for the healthy group and ambulatory sick children, whereas the low risk to the child of the pediatric clinical research study was the second choice for nonambulatory sick children. The least important factor was understanding the study and its regulation.

\section{Improvement factors}

Factors that might have a positive impact on parental consent to the participation of their child in a pediatric clinical research study (Table 3 ) differed significantly ( $\chi^{2}$ test, all $p \leq 0.04$ ), depending on the child's health status. The main factor was "a better understanding of the study and its regulation" for the healthy children and ambulatory sick children groups $(31.2 \%$ and $82.1 \%$, respectively), whereas this was the third factor for the nonambulatory sick children group (50\%).

The modality used for communicating information about the study was the second factor for the healthy and nonambulatory sick groups, whereas a low risk of participating in the study was the second factor for the sick ambulatory group. The least important factor was direct benefit to their own children for both groups.

In addition, we found that $13 \%, 29 \%$, and $40 \%$ of the parents of healthy, ambulatory, and nonambulatory sick children, respectively, would have liked to spend more time with investigators discussing the trial. 
Table 1 Main characteristics of participating parents and children analysed in this survey

\begin{tabular}{|c|c|c|c|c|c|}
\hline & \multirow{2}{*}{$\begin{array}{l}\text { Group } 1 \\
\text { Healthy } \\
\text { children }\end{array}$} & \multirow{2}{*}{$\begin{array}{c}\text { Group } 2 \\
\begin{array}{c}\text { Ambulant sick } \\
\text { children }\end{array}\end{array}$} & \multirow{2}{*}{$\begin{array}{c}\text { Group } 3 \\
\begin{array}{c}\text { Non ambulant sick } \\
\text { children }\end{array}\end{array}$} & \multirow[t]{2}{*}{$\mathrm{P}^{1}$} \\
\hline & & & & & \\
\hline$N(\%)$ & & 48.3 & 37.9 & 13.8 & \\
\hline Age of participating parent (mean year \pm SD) & & $42.1 \pm 6.2$ & $39.3 \pm 5.1$ & $38.5 \pm 3.7$ & $0.91^{*}$ \\
\hline Age of child (mean year $\pm S D$ ) & & $12.3 \pm 1.9$ & $9.8 \pm 3.4$ & $10.1 \pm 3.5$ & $0.82^{*}$ \\
\hline \multicolumn{6}{|l|}{ Gender of participating parent (\%) } \\
\hline & Mother & 82 & 93 & 90 & \multirow[t]{2}{*}{$0.80^{* *}$} \\
\hline & Father & 18 & 7 & 10 & \\
\hline \multicolumn{6}{|l|}{ Parental education level (\%) } \\
\hline & Lower & 32 & 31 & 49 & \\
\hline & Medium & 29 & 47 & 29 & \multirow[t]{2}{*}{$0.004 *$} \\
\hline & High & 39 & 22 & 22 & \\
\hline Children having previously participate to a st & & 10 & 25 & 26 & $0.83^{* *}$ \\
\hline $\begin{array}{l}\text { Children having already heard about clinical } \\
(\%)\end{array}$ & study & 52 & 79 & 87 & $0.002^{* *}$ \\
\hline
\end{tabular}

\section{Discussion}

Children have been the subjects of medical research for hundreds of years, but the present survey is the first to be conducted with adequate statistical power (the computed a posteriori power ranged from $80 \%$ to $>95 \%$ ) that has attempted to identify factors influencing parental consent to the participation of their child in a pediatric clinical research study, according to their health status [14]. The main results of this study were the significant differences in the factors motivating parents and the improvement factors among the three groups. The rank orders of the items in the two questionnaires also differed between the groups.

\section{Participation rate}

As mentioned previously, no reminders were sent in this survey because the survey was completely anonymous and we wanted to determine the actual participation rate without the influence of a reminder. The overall participation rate of our survey was $45.5 \%$, which was comparable to other surveys conducted via the postal service [31].

The health status of the eligible participants was significantly different from that of the analyzed participants ( $x^{2}$ test, $p<0.001$ ). This was mainly due to the high participation rate among parents of sick ambulatory children (the participation rate was $93 \%$ in this group; Figure 1). The groups studied contained different numbers (much smaller in the nonambulatory group) and the participation rates also differed between groups (much higher in sick children), which could have affected the results of our study. However, these differences were expected because sick children are less common than healthy ones but their parents are more enthusiastic/interested in participating in a clinical trial because they expect direct benefits for their children. However, three reasons unrelated to direct health benefits could also have influenced the motivation of

Table 2 Motivation factors from parents to accept their child participating in pediatric clinical research study

\begin{tabular}{|c|c|c|c|c|}
\hline & Group 1 & Group 2 & Group 3 & \multirow[t]{3}{*}{$\mathbf{P}^{*}$} \\
\hline & $\begin{array}{l}\text { Healthy } \\
\text { children }\end{array}$ & $\begin{array}{l}\text { Ambulant sick } \\
\text { children }\end{array}$ & $\begin{array}{l}\text { Non ambulant sick } \\
\text { children }\end{array}$ & \\
\hline & $n=126$ & $n=99$ & $n=36$ & \\
\hline & $\left(\%{ }^{1}\right)$ & $\left(\%^{1}\right)$ & $\left(\%^{1}\right)$ & \\
\hline $\begin{array}{l}\text { Direct benefits to the parent's own child of participating in the } \\
\text { study }\end{array}$ & 85.7 & 100.0 & 100.0 & 0.88 \\
\hline Benefits to the general population & 93.6 & 87.2 & 27.6 & 0.001 \\
\hline Low risk to the child of participating in the study & 100.0 & 60.8 & 70.2 & 0.04 \\
\hline Understanding the study and its regulation & 66.7 & 57.4 & 13.8 & 0.001 \\
\hline
\end{tabular}

${ }^{1}$ Percentage expressed as parent who declared "yes" to the set of question about the item concerned.

${ }^{*} \mathrm{X}^{2}$ Test. 
Table 3 Factors that might have a positive impact on parents' acceptance for their child participating in pediatric clinical research study

\begin{tabular}{|c|c|c|c|c|}
\hline & Group 1 & Group 2 & Group 3 & $\mathbf{P}^{*}$ \\
\hline & $\begin{array}{l}\text { Healthy } \\
\text { children }\end{array}$ & $\begin{array}{l}\text { Ambulant sick } \\
\text { children }\end{array}$ & $\begin{array}{l}\text { Non ambulant sick } \\
\text { children }\end{array}$ & \\
\hline & $n=126$ & $n=99$ & $n=36$ & \\
\hline & $\left(\%{ }^{1}\right)$ & $\left(\%{ }^{1}\right)$ & $\left(\%{ }^{1}\right)$ & \\
\hline Understanding of the study and its regulation & 31.2 & 82.1 & 50.0 & 0.001 \\
\hline Direct benefits to the parent's own child & 12.7 & 19.0 & 20.0 & 0.04 \\
\hline Low risk to the children & 13.5 & 77.4 & 60.0 & 0.001 \\
\hline $\begin{array}{l}\text { The modalities whereby information was communicated about the } \\
\text { study }\end{array}$ & 19.2 & 63.1 & 55.0 & 0.001 \\
\hline
\end{tabular}

${ }^{1}$ Percentage expressed as parent who declared "yes" to the set of question about the item concerned. ${ }^{*} \mathrm{X}^{2}$ Test.

parents: $(i)$ parents with experience of the health care system were more willing to allow their child to be enrolled in a pediatric clinical research study, (ii) some sick children had already participated in a pediatric clinical research study, and (iii) some parents of sick children were already well informed about pediatric clinical research studies by active patient associations or specific organizations that promote clinical research participation (in France, for example, the French Myopathy Association: www.afm-telethon.fr; the Cystic Fibrosis Association:www.vaincrelamuco.org; and www.notrerecherche-clinique.fr/) [32]. Most of the participating parents were the children's mothers, which agreed with other surveys of parents' opinions of pediatric clinical research studies [33].

The question of low risk is also crucial. We found that $100 \%$ of the parents of healthy children considered that low risk was the most important factor. This percentage was lower among parents of sick children $(60.8 \%$ for ambulatory and $70.2 \%$ for nonambulatory sick children), so it was possible to compare the item "low risk" using younger and older parents (median age $=40$ years). We found that $64 \%$ of younger parents considered that "low risk" was the most important factor compared with $36 \%$ of older parents ( $\mathrm{x}^{2}$ test, $p=0.03$ ). This was because older, more experienced parents perceived the risks as lower than younger parents did $[34,35]$.

\section{Motivational factors}

Irrespective of the severity of the pathology, our survey found that the main reason for parents' consenting to their child participating in a pediatric clinical research study was direct benefit to their own child. This agreed with previous parental assessments of the benefit/risk ratio for their child [30,36]. Altruistic motivation was the second reason for the involvement of healthy children and those with low pathology severity. A low risk of participating in a study was also a major reason in all groups. Our results agree with those of Rothmier et al.,
Varma et al., and Nabulsi et al., where the most important factor was the benefit to a parent's own child, while the secondary factor was altruistic motivation [23,25,27]. However, some surveys have found that the main reason was altruistic motivation or a low perceived risk $[18,26,37,38]$. These contradictory results were probably because: $(i)$ the study populations were very different from our survey, and (ii) many other factors can influence the perception of a pediatric clinical research study, such as the parent's personality, religion, ethnicity, socioeconomic status, and level of education [39-43].

\section{Improvement factors}

Similar to the motivational factors, the factors that might improve the likelihood of parents' consenting to their child's participation in a pediatric clinical research study were different between the groups, and they were ranked differently. Indeed, "Understanding of the study and its regulation" was a minor motivational factor, whereas it was the most important improvement factor. "Modalities of information" was a major item that could have a positive impact on parental consent. This item was ranked first because most parents would like to spend more time with physicians discussing pediatric clinical research studies. Our survey found that 13\%, $29 \%$, and $40 \%$ of the parents of healthy, ambulatory, and nonambulatory sick children, respectively, would like to spend more time with investigators discussing pediatric clinical research studies. The following statement concerning the consent process is found in $\mathrm{GCP} / \mathrm{ICH}$ E6/4.8.7: the "investigator [] should provide the subject's or the subject's legally acceptable representative (in the case of this survey, it was parents) ample time and opportunity to inquire about details of the trial and to decide whether or not to participate in the trial (EMEA)" [9]. The same observation (i.e., that parents would like to spend more time with physicians) was also reported by Snowdon et al. [44]. Similar suggestions were 
recorded in other adult and pediatric surveys [45-47]. Parents would prefer to discuss pediatric clinical research studies with investigators directly and to receive greater reassurance before making a decision rather than reading and signing lengthy and complex information/ consent forms, which have increased in length over the years [48]. Previous studies have shown that subjects who were well-informed and who received adequate information about a pediatric clinical research study (e.g., the study's aim, expected benefits, potential adverse events and discomfort, study design, regulation, and study procedure) were more prepared to participate in a pediatric clinical research study, with better compliance and a reduced premature withdrawal rate [49].

Our survey showed that safety was the main concern for the parents of healthy children, whereas the direct benefit of pediatric clinical research studies was the main reason for the parents of sick children, and this was the major motivation for parents' consenting to their children being involved in pediatric clinical research studies. The main improvement factor was clearly that investigators should spend more time discussing pediatric clinical research studies with parents. Indeed, several institutional research centers have already constructed pediatric clinical research centers with specific research teams that include pediatricians, physicians, study nurses, and clinical research assistants, who aim to improve the performance quality of pediatric clinical research studies (www.cic-pediatriques.fr) $[50,51]$. These centers could allow parents to have more personal discussions with staff devoted to pediatric clinical research studies, which appears to be the best method of communicating complex information about pediatric clinical research studies [52-55]. The promotion of pediatric clinical research studies should also consider diverse aspects of pediatric clinical research studies, and the best approaches should be learned during pediatric resident fellowships, as proposed by Massimo et al. and Roth [56,57]. Finally, pediatric investigators and/or pediatric clinical research study sponsors should provide improved and innovative pediatric clinical research study information strategies with specific material, as proposed by Wulf et al. $[24,58]$. Previous successful innovations have included: (i) videotape recordings, (ii) modified consent forms containing figures/pictures, and (iii) a specific handbook that improves knowledge and perceptions of clinical trials [59-61]. Recently, the StaR Child Health group developed evidence-based guidance for the design, conduct, and reporting of pediatric clinical research studies, including recruitment and informed consent in order to reach "agreement on how to best recruit children in an efficient and ethical manner" [62].

\section{Conclusions}

Our survey demonstrated that a child's health status and pathology severity are novel factors that investigators should consider when seeking a parent's consent for child participation in a pediatric clinical research study. Improvements could be made to current practices based on a child's health status and pathology severity to increase the likelihood of parental consent, which may increase the participation rate in pediatric clinical research studies. The main lesson of this survey is that parents would like to spend more time in discussions with investigators before enrolling their child in a pediatric clinical research study.

\section{Additional file}

Additional file 1: Annex 1. Questionnaire on motivational factors and the factors that might improve parental consent.

\section{Abbreviations}

GRP: Good recruitment practices; ISCED: International standard classification of education; GCP/ICH: Good clinical practice/ international conference of harmonization; EMEA: European medicines agency.

\section{Competing interests}

All authors do not have any competing interests.

\section{Authors' contributions}

$L B, L H, F G, C L, D D$ conceived the idea. JV and DB wrote the first and subsequent drafts. SC and SD helped developed the ideas. All authors read and approved the final manuscript.

\section{Acknowledgements}

The authors thank the parents for taking part in the study and J. Salleron for the expertise in the statistical analysis.

\section{Author details}

${ }^{1}$ Centre d'Investigation Clinique, CIC-PT-9301-Inserm-CH\&U, Lille 59037. France. ${ }^{2}$ Unité Inserm U995 \& Université Lille Nord de France, Lille, France. ${ }^{3}$ Comité de Protection des Personnes Nord Ouest IV, Lille, France. ${ }^{4}$ Département de Pharmacologie, Faculté de Médecine, Université Lille Nord de France, Lille, France.

Received: 19 September 2012 Accepted: 12 February 2013

Published: 15 February 2013

\section{References}

1. Ramet J, Van den Anker J: The European Academy of pediatrics (EAP/CESP) and its demand for more clinical research. In Guide to Paediatric Clinical Research. Edited by Rose K, den Naker V. Basel, $\mathrm{CH}$ : 2007:6-12.

2. Smyth $R$, Weindling $A$ : Research in children, ethical and scientific aspects. Lancet 1999, 354:21-24.

3. Caldwell P, Murphy S, Butow SB: Clinical trials in children. Lancet 2004, 364:803-11.

4. Cohen E, Uleryk E, Jasuja M, Parkin PC: An absence of pediatric randomized controlled trials in general medical journals, 1985-2004. J Clin Epidemiol 2007, 60:118-23.

5. Stephenson T: "Bonne année", "gutes neues jahr" ? will 2007 be a "happy new year" for children's medicines in Europe? Arch Dis Child 2007 92:661-63.

6. Pandolfini $\mathrm{C}$, Bonati M: European paediatric research and children's therapeutic needs. A trial review. Acta Paediatr 2008, 97:1232-7.

7. Regulation (EC) No 1901/2006 of the European Parlament and of the Council of 12 December 2006 on medicinal products for paediatric use and amending 
Regulation (EEC) No 1768/92, Directive 2001/20/EC, Directive 2001/83/EC and Regulation (EC) No 726/2004. Available at: http://eur-lex.europa.eu/ LexUriServ/site/en/consleg/2006/R/02006R1901-20070126-en.pdf. Published 2006. Accessed February 20, 2012

8. Directive 2001/20/EC of the European Parliament and of the Council (2001). Approximation of the laws, regulations and administrative provisions of the Member States relating to the implementation of good clinical practice in the conduct of clinical trials on medicinal products for human use. Available at: http://eur-lex.europa.eu/LexUriServ/LexUriServ.do?uri=CELEX:32001 L0020:en: NOT. Published 2001. Accessed April 6, 2012.

9. European Medicines Agency ICH Topic E 6 (R1) guideline for good clinical practice. Available at: http://www.emea.europa.eu/pdfs/human/ich/ 013595en.pdf. Published 2002. Accessed April 6, 2012.

10. PRNewswire. Patient recruitment plays a major role in meeting clinical trial deadlines. Available at: http://www2.prnewswire.com/cgi-bin/stories.pl? ACCT=104\&STORY=/www/story/08-31-2005/0004097079\&EDATE Published 2005. Accessed April 6, 2012.

11. Frank G: Current challenges in clinical trial patient recruitment and enrolment. Available at:http://www.socra.org/pdf/ 200402_Current_Challenges_Recruitment_Enrollment.pdf Published 2004. Accessed September 25, 2011.

12. Bachenheimer JF, Brescia BA: Reinventing patient recruitment. Revolutionary Ideas for clinical trial success: Gower; 2007:1-276.

13. Wilfond BS, Carpenter KJ: Incidental findings in pediatric research. J Law Med Ethics 2008, 36:332-340.

14. Lederer SE, Grodin MA: Historical overview: Pediatric experimentation. In Children as Research Subjects: Science, Ethics, and Law. Edited by Glanz LH. New York, NY: Oxford University Press; 1994:3-25.

15. Costello I, Long P, Wong I: Paediatric Drug Handling. London, UK: The Pharmaceutical Press; 2007.

16. Broome ME: Consent (assent) for research with pediatric patients. Semin Oncol Nurs 1999, 15:96-103.

17. National Commision for the Protection of Human Subjects of Biomedical and Behavorial Research: The Belmont Report: Ethical Principles and Guidelines for the Protection of Human Subjects of Research. Washington, DC: US Government Printing Office; 1979

18. Hayman RM, Taylor BJ, Peart NS, Galland BC, Sayers RM: Participation in research: informed consent, motivation and influence. J Paediatr Child Health 2001, 37:51-54.

19. Pende V, Choonara I, Gennery B: Recruiting children to a clinical trial. Paediatr Perinat Drug Ther 2000, 4:75-78

20. Kaplan S, Brownlee S: Dying for a cure. US News World Rep 1999, 127:34-39.

21. Spilker B: How to improve the quality of clinical trials and their publications. Med Clin 1992, 98:303-4.

22. Hsu DT, Mital S, Ravishankar C, Margossian R, Li JS, Sleeper LA, Williams RV, Levine JC, McCrindle BW, Atz AM, Servedio D, Mahony L, Pediatric Heart Network Investigators: Pediatric heart network investigators rationale and design of a trial of anggiodtensin-converting enzyme in infants with single ventricle. Am Heart J 2009, 157:37-45.

23. Nabulsi M, Khalil Y, Makhoul J: Parental attitudes towards and perceptions of their children's participation in clinical research: a developing-country perspective. J Med Ethics 2011, 37:420-423.

24. Wulf $F$, Krasuska M, Bullinger $G$ : Determinants of decision-making and patient participation in peadiatrc clinical trials: a literature review. Open J Pediatr 2012, 2:2-17.

25. Rothmier D, Lasley MV, Shapiro GG: Factors influencing parental consent in pediatric clinical research. Pediatrics 2003, 111:1037-1041.

26. Tait AR, Voepple-Lewis T, Siewert M: Factors that influence parent's decisions to consent to their child's participation in clinical anesthesia research. Anesth Analg 1998, 86:50-53.

27. Varma S, Jenkins $T$, Wendler D: How do children and parents make decisions about pediatric clinical research? J Pediatr Hematol Oncol 2008 30:823-828.

28. Brody JL, Annett RD, Scherer DG, Turner C, Dalen J: Enrolling adolescents in asthma research: adolescent, parent, and physician influence in the decision-making process. J Asthma 2009, 46:492-497.

29. McCormick A: Stability of the gross motor function classification system after single-event multilevel surgery in cerebral palsy. Dev Med Child Neurol 2012, 54:1073-4.
30. van Stuijvenberg M, Suur MH, de Vos S, Tjiang GC, Steyerberg EW, Derksen-Lubsen G, Moll HA: Informed consent, parental awareness, and reasons for participating in a randomised controlled study. Arch Dis Child 1998, 79:120-125.

31. Beebe TJ, Locke GR 3rd, Barnes SA, Davern ME, Anderson KJ: Mixing web and mail methods in a survey of physicians. Health Serv Res 2006, 42:1219-1233

32. Ondrusek N, Abramovitch R, Pencharz P, Koren G: Empirical examination of the ability of children to consent to clinical research. J Med Ethics 1998, 24:158-165.

33. Tate AR, Calderwood L, Dezateux C, Joshi H: Mother's consent to linkage of survey data with her child's birth records in a multi-ethnic national cohort study. Int J Epidemiol 2006, 35:294-298.

34. Singhal N, Oberle K, Burgess E: Parents' perceptions of research with newborns. J Perinatol 2002, 22:57-63.

35. Chantler TE, Lees A, Moxon ER, Mant D, Pollard AJ, Fiztpatrick R: The role familiarity with science and medicine plays in parents' decision making about enrolling a child in vaccine research. Qual Health Res 2007, 17:311-322.

36. Tait AR, Voepel-Lewis T, Malviya S: Factors that influence parents' assessments of the risks and benefits of research involving their children. Pediatrics 2004, 113:727-732.

37. Langley JM, Halperin SA, Mills EL, Eastwood B: Parental willingness to enter a child in a controlled vaccine trial. Clin Invest Med 1998, 21:12-16.

38. Emanuel EJ, Wood A, Fleischman A, Bowen A, Getz KA, Grady C, Levine C, Hammerschmidt DE, Faden R, Eckenwiler L, Muse CT, Sugarman J: Oversight of human participants research: identifying problems to evaluate reform proposals. Ann Intern Med 2004, 141:282-291.

39. Barsdorf NW, Wassenaar DR: Racial differences in public perceptions of voluntariness of medical research participants in South Africa. Soc Sci Med 2005, 60:1087-1098.

40. Minnies D, Hawkridge T, Hanekom W, Ehrlich R, London L, Hussey G: Evaluation of the quality of informed consent in a vaccine field trial in a developing country setting. BMC Med Ethics 2008, 30:15.

41. Jacobson RM, Ovsyannikova IG, Poland GA: Testing vaccines in pediatric research subjects. Vaccine 2009, 27:3291-3294.

42. Yates FD Jr: Ethics for the pediatrician: religion and spirituality in pediatrics. Pediatr Rev 2011, 32:e91-94.

43. Barakat LP, Patterson CA, Mondestin V, Chavez V, Austin T, Robinson MR, Li Y, Smith-Whitley K, Cohen R: Initial development of a questionnaire evaluating perceived benefits and barriers to pediatric clinical trials participation. Contemp Clin Trials 2012, 34:218-226.

44. Snowdon C, Elbourne D, Garcia J: "It was a snap decision": parental and professional perspectives on the speed of decisions about participation in perinatal randomised controlled trials. Soc Sci Med 2006, 62:2279-2290.

45. Marco CA: Impact of detailed informed consent on research subjects' participation: a prospective, randomized trial. J Emerg Med 2008, 34:269-275.

46. Oduro AR, Aborigo RA, Amugsi D, Anto F, Anyorigiya T, Atuguba F, Hodgson A, Koram KA: Understanding and retention of the informed consent process among parents in rural northern Ghana. BMC Med Ethics 2008, 19:12.

47. Chu SH, Jeong SH, Kim EJ, Park MS, Park K, Nam M, Shim JY, Yoon YR: The views of patients and healthy volunteers on participation in clinical trials: an exploratory survey study. Contemp Clin Trials 2012, 33:611-9.

48. Cressey D: Informed consent on trial. Nature 2012, 482:16.

49. Lynöe N, Sandlund M, Dahlqvist G, Jacobsson L: Informed consent: Study of quality of information given to participants in a clinical trial. BMJ 1991, 303:610-613.

50. Miller TL, Lipshultz SE: Association of medical school pediatric department chairs, Inc. Building a pediatric clinical research division. J Pediatr 2008, 152:1-2.

51. Hankard: Specificity of pediatric clinical research. Arch Pediatr 2009, 16:655-657.

52. Dolan LA, Sabesan V, Weinstein SL, Spratt KF: Preference assessment of recruitment into a randomized trial for adolescent idiopathic scoliosis. J Bone Joint Surg Am 2008, 90:2594-2605.

53. Kodish ED, Pentz RD, Noll RB, Ruccione K, Buckley J, Lange BJ: Informed consent in the childrens cancer group: results of preliminary research Cancer 1998, 82:2467-2481. 
54. Donovan JL, Peters TJ, Noble S, Powell P, Gillatt D, Oliver SE, Lane JA, Neal $D E$, Hamdy FC, ProtecT Study Group: Who can best recruit to randomized trials? Randomized trial comparing surgeons and nurses recruiting patients to a trial of treatments for localized prostate cancer (the ProtecT study). J Clin Epidemiol 2003, 56:605-609.

55. Margitić S, Sevick MA, Miller M, Albright C, Banton J, Callahan K, Garcia M, Gibbons L, Levine BJ, Anderson R, Ettinger W: Challenges faced in recruiting patients from primary care practices into a physical activity intervention trial. Activity Counseling Trial Research Group. Prev Med 1999, 29:277-86.

56. Massimo LM, Wiley TJ, Casari EF: From informed consent to shared: a developing process in paediatric oncology. Lancet Oncol 2004, 5:384-387.

57. Roth DE, Chan MK, Vohra S: Initial successes and challenges in the development of a pediatric resident research curriculum. J Jediatr 2006, 149:149-150.

58. Davies H: Optimisation of informed consent in Paediatric Trials: Best Practice Examples. In The European Forum for Good Clinical Practice Volume Autumn/Winter: 29 \& 30 January 2013. Edited by Wrobel P. Brussels: Clarity Science Communication; 2012:7-8.

59. NCT00870649: ClinicalTrials.gov. Identifier Number for the trial: Efficacy of Vaccine Sh28GST in Association with Praziquantel (PZQ) for Prevention of Clinical Recurrences of Schistosoma Haematobium Pathology (Bilhvax). Available at: www.clinicaltrial.gov. Published 2012. Accessed April 20, 2012.

60. Tait AR, Voepel-Lewis T, Malviya S, Philipson SJ: Improving thge readability and processability of a pediatric informed consent document. Arch Pediatr Adolesc Med 2005, 159:347-352.

61. Campbell HM, Raisch DW, Sather MR, Segal AR, Warren SR, Naik R: Impact of a clinical trial information handbook on patient knowledge, perceptions, and likelihood of participation. IRB 2008, 30:6-14.

62. Hartling L, Wittmeier KDM, Caldwell PH, StaR Child Health: Developing evidence-based guidance for the design, conduct, and reporting of pediatric trials. Pediatrics 2012, 129:112-117.

doi:10.1186/1472-6939-14-7

Cite this article as: Vanhelst et al: Effect of child health status on parents' allowing children to participate in pediatric research. $B M C$ Medical Ethics 2013 14:7.

\section{Submit your next manuscript to BioMed Central and take full advantage of:}

- Convenient online submission

- Thorough peer review

- No space constraints or color figure charges

- Immediate publication on acceptance

- Inclusion in PubMed, CAS, Scopus and Google Scholar

- Research which is freely available for redistribution 